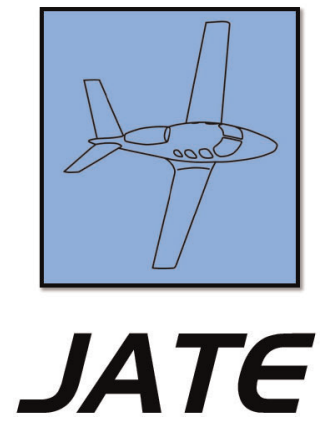

Journal of Aviation Technology and Engineering 7:2 (2018) 67-73

\title{
Assessment of Small Unmanned Aerial Systems Operations in the National Airspace System
}

\author{
Kabir O. Kasim \\ Embry-Riddle Aeronautical University
}

\begin{abstract}
The operation of small unmanned aerial systems (sUAS) in the National Airspace System requires a careful consideration of the operating philosophies to ensure a safe outcome for all users. Small UAS operations are explored while the associated risks and benefits from the operations are reviewed. The operation of sUAS in self-separation airspace is discussed by an examination of the concept of autonomous flight rules (AFR). This includes a presentation of the basic principles of AFR and an explanation of the requirement for a sense-and-avoid system. Current and future uses of sUAS are presented to highlight the benefits from their use. Finally, an overview of the major risks associated with the operation of sUAS is provided in the form of a risk assessment matrix and a hazard/risk process decision chart. Mitigation actions to reduce the risks are also specified along with recommendations for further study.
\end{abstract}

Keywords: $\quad$ small unmanned aerial systems (sUAS), autonomous flight rules (AFR), sense-and-avoid (SAA), risk assessment matrix, hazard/risk process decision chart

\section{Introduction}

Modern applications of unmanned aerial systems (UAS) have outpaced applicable regulations and continue to do so as UAS regulations only now have recently been released. A major attempt at regulation provided in 2013 by the Federal Aviation Administration (FAA) introduced a roadmap for the integration of civil UAS and model aircraft in the National Airspace System (NAS). The document specifically addressed small UAS (sUAS), and proposed a set of rules covering their classification, registration, certification, and operation in the NAS (FAA, 2013).

Further regulatory guidance was provided by the FAA through Advisory Circular (AC) no. 107-2 released in June 2016. The AC specified requirements for conducting sUAS operations in the NAS in accordance with Title 14 of the Code of Federal Regulations (14 CFR) part 107. In the circular, an sUAS is defined as a "small unmanned aircraft (UA) and its associated elements (including communication links and other aircraft components required for small UA airworthiness) that are required for the safe and efficient operation of the small UA in the NAS" (FAA, 2016, p. 4-2). The FAA classification also includes the specification that the UA should weigh less than 55 pounds, and "can be flown without the possibility of direct human intervention from within or on the aircraft" (p. 4-2). Furthermore, the AC helped provide clarity to current and potential users of sUAS in the areas of pilot certification, aircraft registration and airworthiness, as well as in any specific operational requirements for sUAS in the NAS.

All correspondence concerning this article should be directed to Kabir O. Kasim at kasimk@my.erau.edu. 
Small UAS have been commercialized extensively which has allowed technological innovation for aircraft sizes less than $1 \mathrm{~kg}(2.2 \mathrm{lbs})$ at prices comparable to those of smart phones. The technology has also been successfully applied in areas such as crop monitoring, mining, energy, infrastructure, and transportation (Floreano \& Wood, 2015). In addition, UAS technology is expected to continue through large technological innovations that will carry as large an impact as that of how the mobile phone revolutionized human activities and overall socio-economic life quality (Odido \& Madara, 2013). Regardless of how sUAS are applied, their use would involve flights within controlled and uncontrolled airspace. The flights within controlled airspace will require authorization, and the FAA has the responsibility to ensure all aircraft operations (including sUAS) are conducted in a manner that ensures the safe and expeditious flow of air traffic in that airspace (FAA, 2016).

Of the estimated 30,000 UAS in the NAS by year 2020, a substantial number of aircraft will be under direct ownership of law enforcement agencies (Farber, 2015). Current advancements in technology have reduced the overall size of UAS and introduced applications that could be easily adapted to civilian use. For example, two separate studies highlighted the anticipated pervasiveness of sUAS in civilian applications: Frew and Brown (2009) projected that approximately $85 \%$ of the expected 1,500 civil UAS in service by 2017 will be sUAS, while Bloss (2014) found that the numbers of civilians accepting sUAS use for various purposes were: " 88 percent for search and rescue, 67 percent for security, 63 percent for crime fighting and 61 percent for commercial applications" (p. 82).

The purpose of this paper is to present a basic review of a proposal reflecting the viability of sUAS operations in the NAS. A review of extant literature on UAS with emphasis on sUAS will include basic descriptions of the concepts of self-separation airspace, autonomous flight rules (AFR), and sense-and-avoid (SAA) systems. Future uses of sUAS are also described while possible challenges and issues that could result from the operation will be identified. Finally, a discussion of the possible benefits and risks of the operation of sUAS in self-separation airspace will be presented.

\section{Literature Review}

\section{Small Unmanned Aerial Systems in the National Airspace System}

The FAA in 2016 published requirements that mandated sUAS to possess the means to "see and avoid" other aircraft. This helped to clarify some issues regarding the integration of sUAS operations into the NAS. Among other requirements, Federal Aviation Requirements 14 CFR $\S 91.113$ (Right of way rules, 2016) notes that "vigilance shall be maintained by each person operating an aircraft so as to 'see and avoid' other aircraft" (para. b). With this provision from the regulation, pilots are required to selfseparate from other aircraft and maintain separation to ensure they pass well clear of all air traffic (Cole et al., 2013). Regarding the concept of self-separation, Wing and Cotton (2011b) noted that it involves the use of on-board systems and procedures by the pilot of an aircraft to maintain safe and legal distances from other aircraft. Whilst operating in self-separation airspace, it is assumed that aircraft will be operating under AFR, which would be distinct from the usual instrument flight rules (IFR) and visual flight rules (VFR).

The basic principle of sUAS as it relates to their size and weight might imply that this category of aircraft can be operated anywhere with minimal restrictions. It is possible, for example, that sUAS will operate in areas that are impractical for manned flight such as enclosed spaces, near power cables, and very close to buildings and other obstacles (Maroney, 2011). In theory, environments like the situations discussed above may not be part of the NAS, although the FAA, being tasked with the safety of flight in publicuse NAS, has thus set requirements for the registration and accountability for all sUAS operating in the NAS. Depending on the proposed area of operation for example, it may be possible for individual operators and hobbyists to operate sUAS on their own property or within a specified area up to a specific altitude (Logan, 2012).

Commercial applications of sUAS are concerned with operators providing a service for profit and include aerial photography, agriculture, and entertainment. Public use applications, on the other hand, are services that are used for the overall public benefit and are not expected to receive any form of compensation. Public use applications include law enforcement, traffic monitoring, environmental monitoring, and disaster response (Logan, Bland, \& Murray, 2011).

\section{Self-Separation Airspace and Autonomous Flight Rules}

Zografos and Androutsopoulos (2011) noted that the main aim of self-separation is to provide a sustainable solution that can manage the projected increase in the volume of air traffic. They further confirmed that self-separation features the "delegation of the conflict detection and resolution task from the air traffic controllers to the flight crew for a defined part of the airspace" (p. 94). Self-separation requires aircraft to self-position within the airspace using a combination of ground systems technologies and equipment onboard the aircraft. Necessary airborne equipment includes Airborne Separation Assistance System (ASAS) software, complemented by the Traffic Alert and Collision Avoidance System, and Automatic Dependent Surveillance Broadcast (ADS-B). The principle of operation assumes that all aircraft will periodically broadcast information such as position and velocity vector; all aircraft are thus able to selfseparate based on the information (Nakamura \& Takeichi, 2016). Specifically, the ASAS software provides the appropriate 
guidance to ensure separation from other aircraft and from other restricted airspace. The complementary ground systems comprise the System Wide Information Management (SWIM) system and the Traffic Information Service Broadcast system (Wing \& Cotton, 2011a). The SWIM system is also an essential component of the FAA Next Generation Air Transportation System (NextGen) program.

Wing and Cotton (2011a) proposed that aircraft operating under self-separation conditions comply with AFR. They noted that self-separation is the primary enabling capability for achieving the benefits of AFR operations. They further classified AFR as "a structured flight mode with rules and procedures that, while highly flexible, methodically ensures separation safety with the utmost integrity" (p. 4). It is not intended that AFR will replace IFR or VFR, but instead consist of a new set of flight rules to exist along with IFR and VFR. It should be possible to operate in accordance with different sets of rules in one flight depending on the nature and phase of flight. Self-separation will also allow pilots to manage their flights regardless of the flight conditions and with no air traffic control interventions. This should help provide greater capacity for the airspace system (Wing \& Cotton, 2011b). It is also noted that all aircraft within that airspace must be capable of self-separation so that the ideals of self-separation can be realized.

Aircraft operating under AFR will be required to selfseparate from all other IFR, VFR and other AFR aircraft. In addition, self-separation from obstacles, terrain, weather, and any type of restricted airspace will be the responsibility of the operator of the aircraft. The overall objective of the AFR concept is to reduce risk and improve safety by ensuring that traffic monitoring is available on multiple airborne platforms (Wing \& Cotton, 2011a).

\section{Sense and Avoid Systems}

The FAA AC no. 107-2 emphasizes the requirement for UAS to see and avoid other aircraft (FAA, 2016). This requirement can be fulfilled by an SAA system which must "offer a level of safety equaling or exceeding that of manned aircraft" (Yu \& Zhang, 2015, p. 153). An SAA system can be described as an airborne system capable "of determining the presence of potential collision threats, and maneuvering clear of them" (Prats, Delgado, Ramirez, Royo, \& Pastor, 2012, p. 677). A UAS requires an SAA system to provide self-separation and collision avoidance between the UAS and other aircraft or hazards, like the "see and avoid" provision with manned aircraft (Jamoom, Joerger, \& Pervan, 2016; Zeitlin, 2010).

The development of an SAA system capability is one of the major challenges to the integration of sUAS into the NAS (Cole et al., 2013; Prats et al., 2012; Yenson, Cole, Jessee, Crowder, \& Innes, 2015). SAA systems can be either ground-based (GBSAA) or airborne (ABSAA). GBSAA systems use available ground-based radars but are limited to the operational region of the UAS while ABSAA systems are considered long term and can operate without the geographical limitations of GBSAA (Cole et al., 2013). Due to the small size and characteristics of sUAS, traditional SAA systems may not be suitable for sUAS to meet the regulatory requirements. Stark, Stevenson, and Chen (2013) noted that there is a lack of specific SAA systems for sUAS, and suggested that ADS-B integration would complement sense and avoid operations.

\section{Future Applications of Small Unmanned Aerial Systems}

Applications of sUAS have been demonstrated in agriculture, and the current evidence suggests that this use will likely increase (Khot \& Zhou, 2016; Ladd \& Bland, 2009; Rasmussen, Nielsen, Garcia-Ruiz, Christensen, \& Streibig, 2013). Ladd and Bland (2009) categorized the future uses of sUAS under commercial and scientific applications. The commercial applications they highlighted included traffic information gathering, cell phone relay towers, news reporting, and advertising applications. The main scientific applications of sUAS they identified were related to agriculture. This included applications in grain crops, vineyard applications, and organic agriculture. Forestry measurement, management of wetland coastlines, aerial chemistry technology, and mapping of cities using LiDAR (light detection and ranging) were also identified as future scientific applications.

The jobs that sUAS could be tasked to carry out were identified by Bloss (2014) as: "security, safety and resource management at mines and quarries, search for missing on mountains and agricultural tasks such as mapping, cloud diagnostics and parasite and disease monitoring" (p. 82). Floreano and Wood (2015) also described some potential uses of sUAS. These are summarized in Table 1. From the uses listed, the benefits of sUAS are especially important in the delivery of time-sensitive goods and services under conditions that are continuously changing. In addition to this, it also seems likely that their future use will include applications in industries as diverse as medical, agriculture, construction, security, and petroleum.

Amazon, the electronic commerce company, indicated a desire in December 2013 to launch a fleet of UAS within five years to be used in the delivery of packages. While this appears to be a laudable aim, there are significant challenges before this can be achieved. Specifically, Burzichelli (2016) identified the challenges that Amazon could face as: "prohibitive federal regulations, underdeveloped state regulation, growing privacy concerns, and legitimate safety concerns" (p. 162).

\section{Risks of Small Unmanned Aerial Systems Use}

Although sUAS may face certain risks that are like those of manned aircraft, they are also subject to risks that are 
Table 1

Future uses of small unmanned aerial systems.

\begin{tabular}{ll}
\hline Industry & Application \\
\hline Agriculture & Continuously monitor quality of crop growth \\
Mining & Obtain precise volumetric data of excavations \\
Energy and infrastructure & Survey pipelines, roads, and cables \\
Humanitarian organizations & Assess and adapt aid efforts in continuously changing camps \\
Transportation & Allow rapid delivery of essential goods and services \\
Emergency services & Assess dangers in confined spaces safely and rapidly \\
Road maintenance & Measure signs of wear and tear in bridges and tunnels \\
Security & Monitor areas outside the range of surveillance cameras \\
Telecommunication & Drone networks can be used to temporarily supplement or replace points of service
\end{tabular}

Note. Adapted from Floreano and Wood (2015), p. 460.

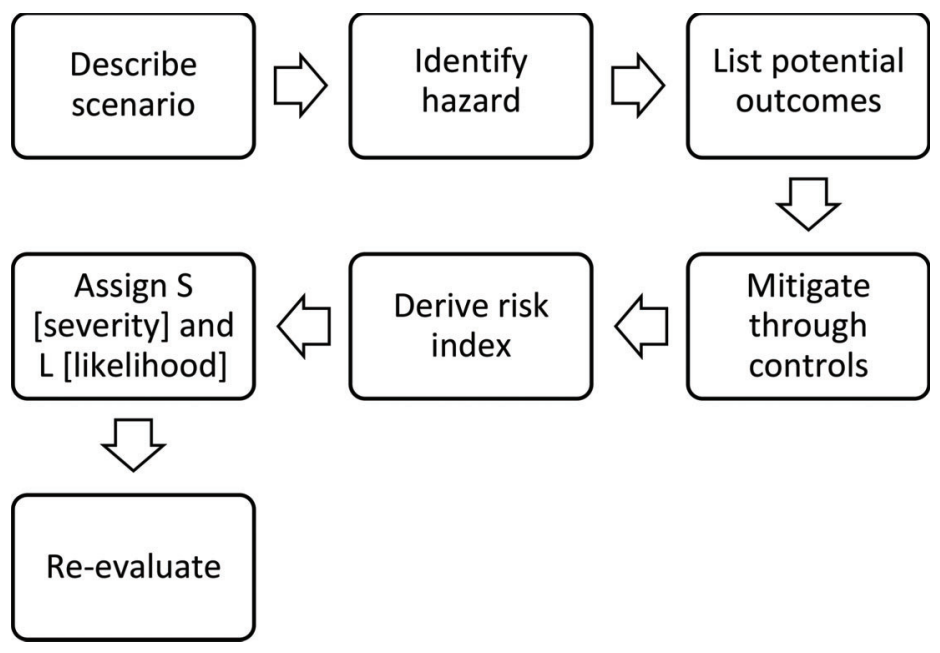

Figure 1. Hazard identification process. Adapted from Stolzer and Goglia (2015).

specific to their operation. The overall risk of sUAS to air traffic was assessed as moderate by Stark et al. (2013) who noted that sUAS "are atypical of manned aircraft operations" (p. 157). One of the main risks in sUAS operations is related to the safety of other airspace users, either onboard a manned aircraft or on the ground. This can be exacerbated by the conduct of sUAS operations by persons with limited aviation training (Cho, 2014). The FAA has published guidelines to ensure that persons wishing to operate sUAS in the NAS possess the appropriate aviation knowledge. Maroney (2011) also suggested that the risk can be mitigated by the restriction of sUAS to specific airspace where there are no manned flights. Regarding the risk to persons on the ground, he suggested the use of operational restrictions such as controlling the movement of persons within the flight path, and design features such as frangibility or the use of parachutes. Frangibility ensures that the sUAS can break up into smaller parts, while parachutes will allow flights to be terminated easily.

\section{Method}

An assessment of the potential risks associated with sUAS operations was conducted using the safety risk management philosophy as described by ICAO (2013). Safety risk management is an essential component of any aviation activity, and sUAS operations require appropriate techniques. The purpose of safety risk management is to "assess the risks associated with identified hazards and develop and implement effective and appropriate mitigations" (ICAO, 2013, p. 2-30). Each potential risk was allocated a risk index as per the ICAO safety risk assessment matrix. Following the application of necessary measures to reduce the risk, a resulting risk index for the hazard is presented.

The process followed to identify and quantify the hazards was adapted from Stolzer and Goglia (2015) and is shown in Figure 1. A hazard/risk process decision program chart for the major risks associated with sUAS operations was also developed.

\section{Results and Discussion}

The risk assessment matrix shown in Table 2 reflects the risk acceptability of the generic hazards of sUAS operations. The generic hazards were selected by the author based on listings of the expected top risks of sUAS operations. The result will be discussed by considering one hazard. 
Table 2

Safety risk assessment matrix.

\begin{tabular}{|c|c|c|c|c|c|}
\hline \multirow[t]{2}{*}{ Risk Probability } & \multicolumn{5}{|c|}{ Risk Severity } \\
\hline & Catastrophic A & Hazardous B & Major C & Minor D & Negligible $\mathbf{E}$ \\
\hline Frequent 5 & $5 \mathrm{~A}$ & $5 \mathrm{~B}$ & $5 \mathrm{C}$ & $5 \mathrm{D}$ & $5 \mathrm{E}$ \\
\hline Occasional 4 & $4 \mathrm{~A}$ & $4 \mathrm{~B}$ & $4 \mathrm{C}$ & $4 \mathrm{D}$ & $4 \mathrm{E}$ \\
\hline Remote 3 & $3 \mathrm{~A}$ & 3B & $3 C$ & $3 \mathrm{D}$ & $3 \mathrm{E}$ \\
\hline Improbable 2 & $2 \mathrm{~A}$ & $2 \mathrm{~B}$ & $2 \mathrm{C}$ & $2 \mathrm{D}$ & $2 \mathrm{E}$ \\
\hline $\begin{array}{l}\text { Extremely } 1 \\
\text { improbable }\end{array}$ & $1 \mathrm{~A}$ & 1B & $1 \mathrm{C}$ & $1 \mathrm{D}$ & $1 \mathrm{E}$ \\
\hline
\end{tabular}

Note. Adapted from ICAO (2013), p. 2-29. _ _, Unacceptable; __ , Acceptable with mitigation; _ _, Acceptable.

\begin{tabular}{|c|c|c|c|c|c|}
\hline \multicolumn{6}{|c|}{ Hazard/Risk Process Decision Chart for sUAS operations } \\
\hline $\begin{array}{l}\text { Type of } \\
\text { operation or } \\
\text { activity }\end{array}$ & $\begin{array}{l}\text { State of the generic } \\
\text { hazard (hazard } \\
\text { statement) }\end{array}$ & $\begin{array}{l}\text { Initial Risk } \\
\text { Index }\end{array}$ & $\begin{array}{l}\text { Current measures to reduce } \\
\text { risk }\end{array}$ & Further action to reduce risk & $\begin{array}{l}\text { Resulting Risk } \\
\text { Index }\end{array}$ \\
\hline \multirow{4}{*}{$\begin{array}{c}\text { sUAS } \\
\text { Operations }\end{array}$} & $\begin{array}{l}\text { sUAS malfunction or } \\
\text { lost link due to } \\
\text { bandwidth }\end{array}$ & 3A & $\begin{array}{l}\text { Mobile networking } \\
\text { configurations, redundant } \\
\text { design, auto landing }\end{array}$ & $\begin{array}{l}\text { Operational restrictions - line } \\
\text { of sight only, restriction of } \\
\text { persons in operating areas }\end{array}$ & 3D \\
\hline & $\begin{array}{l}\text { Mid-air collision with } \\
\text { other sUAS,object or } \\
\text { manned aircraft }\end{array}$ & 3A & $\begin{array}{l}\text { Redundant design, auto } \\
\text { landing capability }\end{array}$ & $\begin{array}{l}\text { Operations limited to visual } \\
\text { flight rules, sUAS operators in } \\
\text { contact with nearest ATCs }\end{array}$ & 3D \\
\hline & $\begin{array}{l}\text { Collision with objects } \\
\text { or other persons on } \\
\text { ground }\end{array}$ & 3A & $\begin{array}{l}\text { Redundant design, auto } \\
\text { landing capability }\end{array}$ & $\begin{array}{l}\text { Operations limited to visual } \\
\text { flight rules , restriction of } \\
\text { persons in operating areas }\end{array}$ & 3D \\
\hline & $\begin{array}{l}\text { Inexperienced } \\
\text { operators }\end{array}$ & 3A & $\begin{array}{l}\text { National sUAS pilot } \\
\text { qualification standards }\end{array}$ & $\begin{array}{l}\text { Operational restrictions, } \\
\text { additional observer for specific } \\
\text { missions }\end{array}$ & 3D \\
\hline
\end{tabular}

Figure 2. Hazard/risk process decision chart for sUAS operations. Developed by the author.

For example, the presence of inexperienced operators in self-separation airspace was determined to be a potential hazard. The likelihood of an inexperienced operator was assessed as remote, meaning it is unlikely to occur, but possible. The corresponding risk probability is "3." The safety risk severity was assessed as "A," meaning equipment destroyed and/or multiple deaths. The overall risk index is therefore $3 \mathrm{~A}$ which means that it is unacceptable for this operation to proceed. The choices before the operator are therefore as follows: take measures to reduce the exposure to the risk, take measures to reduce the severity of consequences, or cancel the operation (ICAO, 2013). The next step in this process seeks to identify appropriate measures to reduce this risk. Some actions outlined by the FAA (2017) to deter unsafe UAS operations include identification of witnesses and operators, viewing and recording locations, immediate notification, and evidence collection. In this case, it was considered that enforcing sUAS pilot qualification standards, introducing operational restrictions, and including an additional observer during specific missions are measures that could be applied.

A re-evaluation of this risk resulted in a risk index of $3 \mathrm{D}$, which is acceptable with mitigation. This operation can therefore proceed but the mitigation strategies must be strictly enforced. The implication is that if any of the mitigation measures are unavailable or unworkable, the operation cannot proceed. The other major hazards identified were sUAS malfunction or lost link due to bandwidth, mid-air collision with other sUAS, object or manned aircraft, and collision with objects or other persons on the ground. These hazards were all assessed with an initial risk index of $3 \mathrm{~A}$, which is unacceptable. Following the application of measures to reduce risk, the resulting risk index was adjudged acceptable with mitigation (3D).

The hazard/risk process decision chart for major hazards in sUAS operations showing the initial risk index and the resulting risk index after the mitigation measures is shown in Figure 2.

The safety risk assessment process is an integral part of the safety management system (SMS) of air transport operators. Since the nature of air transport and aviation operations implies that there is some element of risk involved, an operator must conduct and document this process for its own use, and to fulfil regulatory requirements. Small UAS pilots or operators have the responsibility to ensure their operations have developed appropriate 
"risk acceptance procedures, including acceptance criteria and designation of authority and responsibility for risk management decision making" (FAA, 2016, p. A-4).

\section{Conclusion and Recommendations}

The focus of this paper identifies safety risk management as one of the four components of safety management, the others being safety policy, safety assurance, and safety promotion. It is essential that all components are in place for an effective SMS (FAA, 2015).

The FAA has attempted to address the proliferation of UAS and sUAS by updating current regulations and by releasing operational guidelines. Guidance on the operation of sUAS in the NAS was provided by the FAA through the publication of AC no. 107-2. It is important to note that the overriding objective of the regulations is to ensure a safe operating environment for all airspace users. The assessment of sUAS operations discussed in this paper focused on the potential uses and the associated risks. The concept of AFR airspace and how it can provide airspace users with a functional alternative to the two standard flight rules (VFR and IFR) is also discussed. AFR also supports the NextGen vision for self-separation (Wing \& Cotton, 2011a).

Although the presented hazard/risk process decision chart presented in this paper is not expected to be a comprehensive list of all sUAS hazards in self-separation airspace, it highlights the greatest risks and provides a brief overview of sUAS operations. While the pilot in command ultimately has the overall responsibility for air transport operations, all personnel connected with the operation should be involved in the analysis of the risks before the commencement of the operation. It is recommended that further studies be conducted on the use of SAA technologies in reducing the risk of sUAS operations. Further studies are also proposed in the form of detailed root cause analysis and cost-benefit analysis to properly evaluate the concepts.

\section{References}

Bloss, R. (2014). Unmanned vehicles while becoming smaller and smarter are addressing new applications in medical, agriculture, in addition to military and security. The Industrial Robot, 41(1), 82. https://doi.org/ 10.1108/IR-03-2013-410

Burzichelli, C. D. (2016). Delivery drones: Will Amazon Air see the National Airspace. Rutgers Computer \& Technology Law Journal, 42(1), 162-195.

Cho, Y. (2014). Lost in debate: The safety of domestic unmanned aircraft systems. Journal of Strategic Security, 7(4), 38-56. https://doi.org/ 10.5038/1944-0472.7.4.4

Cole, R., Kochenderfer, M. J., Weibel, R., Edwards, M. W., Griffith, J. D., \& Olson, W. (2013). Fielding a sense and avoid capability for unmanned aircraft systems: Policy, standards, technology, and safety modeling. Air Traffic Control Quarterly, 21(1), 5-27. Retrieved from https://doi.org/10.2514/atcq.21.1.5
FAA. (2013). Integration of civil unmanned aircraft systems (UAS) in the National Airspace System (NAS) roadmap. Retrieved from https:// www.faa.gov/uas/media/uas_roadmap_2013.pdf

FAA. (2015). SMS for aviation service providers (Advisory Circular 120-92B). Retrieved from http://www.faa.gov/documentLibrary/ media/Advisory_Circular/AC_120-92B.pdf

FAA. (2016). Small unmanned aircraft systems (sUAS) (Advisory Circular 107-2). Retrieved from http://www.faa.gov/uas/media/AC_107-2_ AFS-1_Signed.pdf

FAA. (2017). Law enforcement guidance for suspected unauthorized UAS operations. Retrieved from https://www.faa.gov/uas/resources/law_ enforcement/media/FAA_UAS-PO_LEA_Guidance.pdf

Farber, H. B. (2015). Eyes in the sky and privacy concerns on the ground. SciTech Lawyer, 11(4), 6-9. Retrieved from https://www.americanbar. org/content/dam/aba/publications/scitech_lawyer/2015/summer/ scitech_lawyer_summer_2015_issue.authcheckdam.pdf

Floreano, D., \& Wood, R. J. (2015). Science, technology and the future of small autonomous drones. Nature, 521(7553), 460-466. https://doi.org/ 10.1038 /nature 14542

Frew, E. W., \& Brown, T. X. (2009). Networking issues for small unmanned aircraft systems. Journal of Intelligent and Robotic Systems, 54(1-3), 21-37. https://doi.org/10.1007/s10846-008-9253-2

ICAO. (2013). Safety management manual (Doc. 9859). Retrieved from http://www.icao.int/safety/SafetyManagement/Documents/Doc.9859. 3rd\%20Edition.alltext.en.pdf

Jamoom, M. B., Joerger, M., \& Pervan, B. (2016). Unmanned aircraft system sense-and-avoid integrity and continuity risk. Journal of Guidance, Control, and Dynamics, 39(3), 498-509. https://doi.org/10.2514/1.G001468

Khot, L. R., \& Zhou, J. (2016). Precision agriculture: Beyond the domain of small UAS. Resource, 23(3), 20-21.

Ladd, G. B., \& Bland, G. L. (2009). Non-military applications for small UAS platforms. In AIAA Infotech@ Aerospace Conference and AIAA Unmanned... Unlimited Conference (p. 2046). https://doi.org/10.2514/ 6.2009-2046

Logan, M. (2012, January). Examination of frameworks for safe integration of intelligent small UAS into the NAS. In 50th AIAA Aerospace Sciences Meeting including the New Horizons Forum and Aerospace Exposition (p. 960). Retrieved from https://ntrs.nasa. gov/archive/nasa/casi.ntrs.nasa.gov/20120001335.pdf

Logan, M., Bland, G., \& Murray, J. (2011). A framework for safe integration of small UAS into the NAS. Proceedings of the 11th AIAA Aviation Technology, Integration, and Operations (ATIO) Conference, including the 19th AIAA Lighter Than-Air Technology Conference and the AIAA Balloon Systems Conference. https://doi.org/10.2514/ 6.2011-6936

Maroney, D. R. (2011, September). Rethinking airspace definitions for small UAS. In Proceedings of the 11th AIAA Aviation Technology, Integration, and Operations (ATIO) Conference (pp. 20-22). https:// doi.org/10.2514/6.2011-6958

Nakamura, Y., \& Takeichi, N. (2016). A self-separation algorithm for width-limited high density air corridor. Proceedings of the Institution of Mechanical Engineers, 230(9), 1632-1640. https://doi.org/10.1177/ 0954410015620446

Odido, D., \& Madara, D. (2013). Emerging technologies: Use of unmanned aerial systems in the realization of vision 2030 goals in the counties. International Journal of Applied Science and Technology, 3(8). Retrieved from http://www.ijastnet.com/journals/Vol_3_No_8_ December_2013/15.pdf

Prats, X., Delgado, L., Ramirez, J., Royo, P., \& Pastor, E. (2012). Requirements, issues, and challenges for sense and avoid in unmanned aircraft systems. Journal of Aircraft, 49(3), 677-687. https://doi.org/ 10.2514/1.C031606

Rasmussen, J., Nielsen, J., Garcia-Ruiz, F., Christensen, S., \& Streibig, J. C. (2013). Potential uses of small unmanned aircraft systems (UAS) in weed research. Weed Research, 53(4), 242-248. https://doi.org/ $10.1111 /$ wre. 12026 
Right-of-way rules: Except water operations, 14 C.F.R. $\$ 91.113$ (2016). Retrieved from http://www.ecfr.gov/cgi-bin/text-idx?rgn= div8\& node $=14: 2 \cdot 0.1 \cdot 3 \cdot 10 \cdot 2 \cdot 4.7$

Stark, B., Stevenson, B., \& Chen, Y. (2013). ADS-B for small unmanned aerial systems: Case study and regulatory practices. Proceedings of the 2013 International Conference on Unmanned Aircraft Systems (ICUAS) (pp. 152-159). https://doi.org/10.1109/ICUAS.2013.6564684

Stolzer, A. J., \& Goglia, J. J. (2015). Safety management systems in aviation (2nd ed.). Burlington, VT: Ashgate.

Wing, D. J., \& Cotton, W. B. (2011a). Autonomous flight rules: A concept for self-separation in U.S. domestic airspace (report no. NASA/TP2011-217174). Retrieved from http://ntrs.nasa.gov/archive/nasa/casi. ntrs.nasa.gov/20110023668.pdf

Wing, D. J., \& Cotton, W. B. (2011b, September). For spacious skies: Selfseparation with "autonomous flight rules" in US domestic airspace. In Proceedings of the 11th AIAA Aviation Technology, Integration, and Operations (ATIO) Conference (pp. 20-22). https://doi.org/10.2514/6. 2011-6865

Yenson, S. K., Cole, R. E., Jessee, M. S., Crowder, C., \& Innes, J. (2015). Ground-based sense and avoid: Enabling local area integration of unmanned aircraft systems into the National Airspace System.
Air Traffic Control Quarterly, 23(2-3), 157-182. https://doi.org/10.2514/ atcq.23.2-3.157

Yu, X., \& Zhang, Y. (2015). Sense and avoid technologies with applications to unmanned aircraft systems: Review and prospects. Progress in Aerospace Sciences, 74, 152-166. https://doi.org/10.1016/ j.paerosci.2015.01.001

Zeitlin, A. D. (2010). Sense and avoid capability development challenges. IEEE Aerospace and Electronic Systems Magazine, 25(10), 27-32. https://doi.org/10.1109/MAES.2010.5631723

Zografos, K., \& Androutsopoulos, K. (2011). Economic and institutional impacts of introduction of self-separation concept of operations in air traffic management. Transportation Research Record: Journal of the Transportation Research Board, 2214, 94-102. https://doi.org/10. $3141 / 2214-12$

Kabir Kasim is a holder of an Air Transport Pilots License (Helicopter) and completed an MSc in air transport management. He is currently a $\mathrm{PhD}$ student at Embry-Riddle Aeronautical University. His research interests include human factors, pilot training, safety management, and performance-based navigation. 